\title{
Testicular and inguinal lymph node metastases of medullary thyroid cancer: a case report and review of the literature
}

\author{
Marialuisa Appetecchia ${ }^{1 *}$, Agnese Barnabei ${ }^{1}$, Vincenzo Pompeo ${ }^{2}$, Steno Sentinelli ${ }^{3}$, Roberto Baldelli ${ }^{1}$, \\ Salvatore Maria Corsello ${ }^{4}$ and Francesco Torino ${ }^{5}$
}

\begin{abstract}
Background: The involvement of the testis by metastatic medullary thyroid carcinoma has never been described before. We describe the first case of metastatic medullary thyroid carcinoma affecting testis and inguinal lymph nodes.

Case presentation: A 73-year-old Caucasian man was referred to undergo urologic surgery due to a painless nodule in the right testis and an homolateral inguinal lymphoadenomegaly. The patient had a history of medullary thyroid carcinoma with relapsing disease to the spine and lung nodules. Serum calcitonin and CEA levels were $175 \mathrm{pg} / \mathrm{ml}$ and $22 \mathrm{ng} / \mathrm{ml}$, respectively. With suspected testicular cancer, the patient underwent radical right orchiectomy with the excision biopsy of the right inguinal lymph node. Histopathology and immunohistochemistry revealed that both the lesions were due to metastases from medullary thyroid carcinoma.

Conclusion: Metastases to the testis and inguinal lymph nodes may be due to various solid and hematological tumors. This case, despite its rarity, suggests that testis and inguinal lymph nodes should be considered as potential secondary sites of medullary thyroid carcinoma as well.
\end{abstract}

Keywords: Medullary thyroid cancer, Testicular metastasis, Inguinal lymph node metastasis

\section{Background}

Medullary thyroid carcinoma (MTC) is a neuroendocrine tumor that arises from the thyroid parafollicolar calcitonin producing $\mathrm{C}$ cells and accounts for about $5 \%$ of thyroid carcinomas [1]. MTC mainly presents as a sporadic disease, but in approximately $20 \%$ of cases is hereditary. Specific germline mutations in the rearranged during transfection proto-oncogene ( $R E T)$ have a pathogenic role in the onset of familial MTC (FMTC) or MEN2, the two clinical forms of hereditary MTC [2-4]. In these patients, RET mutations predict prognosis and guide the choice of treatment timing and follow-up. However, genetic testing for germline RET mutations is recommended not only for screening children and adults in known kindreds with

\footnotetext{
* Correspondence: appetecchia@ifo.it

${ }^{1}$ Regina Elena National Cancer Institute, Endocrinology Unit, Via Elio Chianesi 53, I- 00144 Rome, Italy

Full list of author information is available at the end of the article
}

inherited forms of MTC, but also for all newly diagnosed patients with clinically apparent sporadic MTC $[1,2]$.

Sporadic MTC usually manifests in the fifth-sixth decade, while familial forms have an earlier onset [1]. MTC usually presents as a palpable neck mass due to thyroid nodule(s) and in 30-50\% of cases it is accompanied by metastases in cervical/paratracheal lymph nodes. Upper and anterior mediastinal lymph nodes are also in the pathway of tumor spread, but symptoms related to aerodigestive tract compression/invasion are reported by up to $15 \%$ of patients [5]. Distant metastases are present at the diagnosis in $10-15 \%$ of patients. Preferred sites of metastatic spread include lung, liver and bone [6]. Metastases to brain, adrenal glands, pleura, heart, ovary, pancreas, pituitary, retina, skin and breast have been rarely/exceptionally reported [7-9].

Compared with papillary/follicular thyroid cancer, MTC is more aggressive having a higher rate of recurrence and increased mortality [10]. Older age, larger tumor size, 
involvement of regional lymph nodes and distant metastases correlate with worse prognosis as well as high calcitonin and carcinoembrionic antigen (CEA) serum levels [11]. The clinical course of advanced/metastatic MTC is unpredictable. Lung or bone metastases may initially cause symptoms in only $5-10 \%$ of patients. Survival in patients with newly diagnosed distant metastases is $51 \%$ at 1 year, $26 \%$ at 5 years and $10 \%$ at 10 years $[10,12,13]$.

Surgery is the main treatment for primary MTC and for local and distant metastases, whenever feasible. External-beam radiation to the neck/upper mediastinum is useful in patients with extrathyroidal disease or extensive nodal metastases not undergoing curative resection and for palliative purposes [2]. Cytotoxic chemotherapy is used in patients with metastatic/unresectable MTC, but is poorly effective [6]. Recently, vandetanib and cabozantinib, two oral multikinase inhibitors improved survival in patients with advanced/metastatic MTC and are licensed for the treatment of these patients [14]. Several experimental drugs, mainly kinase inhibitors, are under clinical evaluation $[15,16]$.

Herein, we report the case of a patient with MTC that metastasized to the right testis and to an homolateral inguinal lymph node, many years later to the detection of skeletal and lung metastases.

\section{Case presentation}

In 2002, a 63 year old Caucasian man presenting a large solitary nodule in the upper right lobe of thyroid was cytologically diagnosed with medullary thyroid carcinoma (MTC). No family history of MTC or multiple endocrine neoplasia (MEN) was reported. Appropriate endocrine work up excluded MEN2. Preoperative serum calcitonin was $122 \mathrm{pg} / \mathrm{ml}$ (reference range: 0-9.6 pg/ml) with normal carcinoembryonic antigen (CEA) serum levels. The patient underwent total thyroidectomy and bilateral neck lymph node dissection. Histology confirmed a $52 \mathrm{~mm}$ in diameter MTC confined to thyroid without metastases in the 54 resected lymph nodes (stage III; UICC 2002). The genetic testing identified the non-conservative functional c.2071G > A polymorphism in codon 691 of the RET proto-oncogene that was not mutated.

During the follow-up calcitonin (basal and after pentagastrin stimulation) and CEA were in the normal range until September 2008, when basal calcitonin started to slightly increase (up to $64 \mathrm{pg} / \mathrm{ml}$ ). Neck ultrasound was negative, but contrast-enhanced computed tomography scan (CT-scan) showed diffused lung micronodules. Then, the $99 \mathrm{mTc}-\mathrm{MDP}$ bone scan showed an uptake area at the pedicle and right lamina of the fifth lumbar vertebra (November 2009) and 18-Fluorodeoxyglucose Positron Emission Tomography $\left({ }^{18} \mathrm{FDG}-\mathrm{PET}\right)$ and ${ }^{68} \mathrm{Ga}$ DOTATOC-PET confirmed the fifth lumbar vertebra as the only metastatic site. In 2011, the disease progressed (at bone scan the known uptake area enlarged and a new pathologic area appeared in the right hemisacrum). Bone lesions were osteoblastic on X-ray evaluation. Lung metastases remained stable in the absence of new lesions at CT-scan. Serum calcitonin and CEA levels were $141 \mathrm{pg} / \mathrm{ml}$ and $21 \mathrm{ng} / \mathrm{ml}$, respectively. The patient was still asymptomatic.

In March 2012, the patient presented with a painless nodule in the right testis and a palpable right inguinal lymph node. Ultrasound showed an hypoechoic and inhomogenous solid mass of $17 \mathrm{~mm}$ in size in the upper lobe of the right testis and a $2 \mathrm{~cm}$ inguinal lymph node (Figure 1). $\beta$-human chorionic gonadotropin ( $\beta$-HCG), $\alpha$-fetoprotein and lactate dehydrogenase were normal. Calcitonin was $175 \mathrm{pg} / \mathrm{ml}$, CEA $22 \mathrm{ng} / \mathrm{ml}$. CT-scan showed a slight increase in two lung nodules (each $1 \mathrm{~cm}$ in diameter).

Given that primary testicular cancer was suspected, the patient underwent right radical orchiectomy and excision of the inguinal lymph node. Histology revealed the presence of metastases, morphologically resembling MTC, both in the testis $(2.2 \mathrm{~cm}$ in diameter) where tumor cells infiltrated the rete testis, and in the inguinal lymph node. Immunohistochemistry showed reactivity for AE1/AE3, TTF-1 calcitonin and chromogranin, but not for CD30, actin- $\mu$ and vimentin, thus confirming the diagnosis of metastases from MTC (Figure 2).

Post-surgery calcitonin and CEA levels decreased, but did not normalize. Recently, progressive disease was documented in the lung, bone and inguinal lymph nodes. The patient is still asymptomatic, but is going to start vandetanib.

\section{Discussion}

Testicular metastases are extremely rare, except in patients affected by leukemia or lymphoma [17]. Metastases to the testis from solid tumors may be discovered incidentally at autopsy or following therapeutic/diagnostic orchiectomy, as in the case presented. In autopsy series that included non-neoplastic deaths, testicular metastases were found in $0.02 \%$ to $2.5 \%$ of specimens [17-21]. In other series of patients who underwent orchiectomy for testicular malignancy, testicular metastases were detected in up to $7 \%$ of patients, the common primary malignancy being prostate, melanoma, sarcoma, lung, urologic and gastrointestinal cancer (Table 1) [22-27]. Less frequently urinary bladder and pancreatic tumors or neuroblastoma metastasize to the testis [28]. Bilateral involvement of the testis occurs in about $15 \%$ of cases [17-27]. Involvement of the testis is usually accompanied by cancer spreading to other sites, rarely affecting survival that remains largely dependent on the burden and aggressiveness of the underlying disease and the vital importance of involved organs. Surgery, if indicated, 

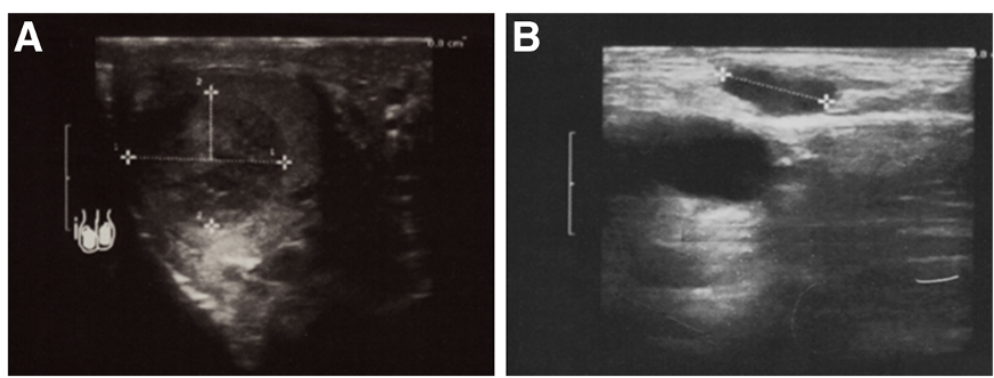

Figure 1 Ultrasound images show a solid and inhomogeneous hypoechoic mass in the upper lobe of the right testis (A) and a right inguinal lymphoadenopathy $2 \mathrm{~cm}$ in diameter (B).

is the preferred therapy of testicular metastases from solid malignancies. Testicular metastasis from MTC has never been reported.

The mechanisms of metastatic spread to the testis is still speculative. It has been suggested that metastases from solid tumors might join testis via retrograde arterial, venous or lymphatic embolization [29]. Specific spreading routes have been associated with certain solid tumors, including arterial embolism from lung cancer [30], retrograde venous spread in renal cell carcinoma [29] or retrograde lymphatic spread in gastrointestinal, prostate and urinary bladder cancer $[28,29,31]$. In an anatomic study of spermatic veins, Wishami et al. demonstrated connections between spermatic and renal
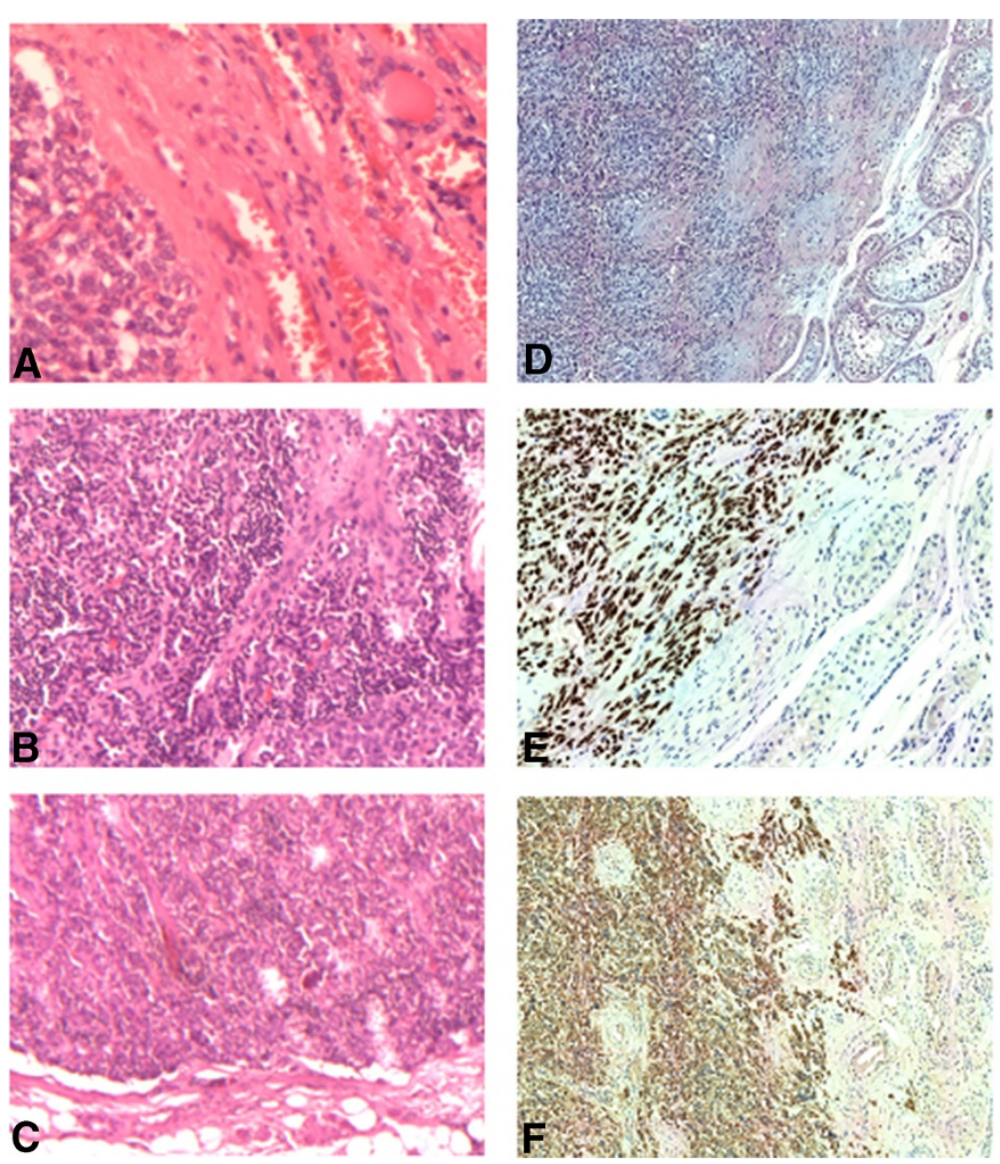

Figure 2 Histological and immunohistochemical examinations. A, B: Histology of primary medullary thyroid cancer; C: Metastasis of medullary thyroid carcinoma in the right inguinal lymph node; $\mathbf{D}$ : The right testis: histological examination shows trabecular solid areas with round and spindle cells of medullary thyroid carcinoma, partially separated by fibrous stroma infiltrating testicular parenchyma. Immunohistochemistry: Tumor cells show diffuse cytoplasmic positivity for TTF-1 (E) and with calcitonin (F). 
Table 1 Selected case series reporting metastases to the testis

\begin{tabular}{|c|c|c|c|c|}
\hline Authors & $\begin{array}{l}\text { Diagnostic/therapeutic/ } \\
\text { autopsy series }\end{array}$ & $\begin{array}{l}\text { Total number of } \\
\text { patients included }\end{array}$ & $\begin{array}{l}\text { N. of patients with } \\
\text { testicular metastases (\%) }\end{array}$ & Primary solid tumors (\%) \\
\hline Pienkos et al. [20] & Autopsy & 24,000 & $15(0.06)$ & $\begin{array}{l}\text { Lung } 7 \text { (46.6); Melanoma } 2 \text { (13.2); } \\
\text { Ureter } 1 \text { (6.7); Kidney } 1 \text { (6.7); Rectum } \\
1 \text { (6.7); Salivary gland } 1 \text { (6.7); Pancreas } \\
1 \text { (6.7); Unknown } 1 \text { (6.7). }\end{array}$ \\
\hline Nistal et al. [28] & Autopsy & 3,474 & $5(0.14)$ & $\begin{array}{l}\text { Pancreatic } 1 \text { (20); urinary bladder } 1 \\
\text { (20); prostate } 1 \text { (20); neuroblastoma } \\
2 \text { (40). }\end{array}$ \\
\hline Tiltman AJ. [18] & Autopsy & 2,271 & $6(2.5)$ & $\begin{array}{l}\text { Prostate } 2 \text { (33.3); melanoma } 2 \text { (33.3); } \\
\text { lung } 1 \text { (16.7); pleural mesothelioma } \\
1 \text { (16.7) }\end{array}$ \\
\hline García-González et al. [21] & Autopsy & 780 & $5(0.64)$ & $\begin{array}{l}\text { Lung } 3 \text { (60); melanoma } 1 \text { (20); } \\
\text { pancreatic endocrine carcinoma } 1 \\
\text { (20). }\end{array}$ \\
\hline Patel et al. [23] & Autopsy/diagnostic/therapeutic & 550 & $20(3.6)$ & $\begin{array}{l}\text { Prostate } 12(60) \text {, melanoma } 3(15) \text {, } \\
\text { sarcoma } 2 \text { (10), lung } 1(5) \text {, colon } 1 \\
\text { (5), renal carcinoma } 1 \text { (5) }\end{array}$ \\
\hline Sharma et al. [25] & Diagnostic/therapeutic & 300 & $10(3.33)$ & $\begin{array}{l}\text { Prostate } 6 \text { (60); lung } 1 \text { (10); lanynx } 1 \\
\text { (10); kidney } 1 \text { (10); colon (10). }\end{array}$ \\
\hline Lu et al. [26] & Diagnostic & 200 & $14(7)$ & $\begin{array}{l}\text { Prostate } 8 \text { (57.1); Lung } 2 \text { (14.3); } \\
\text { Esophagus } 1 \text { (7.1); Seminal } \\
\text { vescicles } 1 \text { (7.1); Sigmoid colon } \\
1 \text { (7.1); Unknown } 1 \text { (7.1). }\end{array}$ \\
\hline Dutt et al. [19] & Autopsy/diagnostic/therapeutic & 31 & 22 & 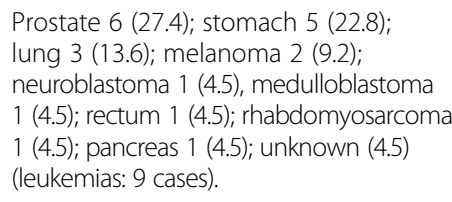 \\
\hline Ulbright et al. [27] & Diagnostic & 26 & 26 & $\begin{array}{l}\text { Prostate } 11(42.3) \text {; renal } 4(15.4) \text {; colon } \\
4(15.4) \text {; urinary tract } 3(11.5) \text {; lung } 2 \\
\text { (7.7); esophagus } 1 \text { (3.8); small intestine } \\
1 \text { (3.9). }\end{array}$ \\
\hline Grignon et al. [22] & Diagnostic/autopsy & 18 & 18 & $\begin{array}{l}\text { Lung } 9(50) \text {, prostate } 4(22.2) \text {, stomach } \\
4(22.2) \text {, bile tract } 1(5.6) \text {. }\end{array}$ \\
\hline Bhasin et al. [24] & Diagnostic/therapeutic & 10 & 10 & $\begin{array}{l}\text { Prostate } 4 \text { (40); gastrointestinal } 4 \text { (40); } \\
\text { kidney } 2 \text { (20). }\end{array}$ \\
\hline
\end{tabular}

capsular veins and between spermatic and ipsilateral colonic veins. These findings may sustain the retrograde venous spread from both kidney and colon cancer [32]. Moreover, the absence of valves in spermatic veins has been suggested as a favoring factor for the retrograde spread from the renal veins or the retroperitoneum [31]. Metastases from prostatic carcinoma and seminal vesicle cancer may reach testis via direct extension and intraductal spread via the vas deferens and epididymis [22,23].

In patients presenting a solitary testicular mass, the differential diagnosis must include metastatic carcinoma. A personal history of cancer should first be investigated. Older age is suggestive of a secondary testicular tumor. Measurement of serum $\alpha$-fetoprotein and $\beta$-HCG, if negative, does not exclude a testicular primary germ cell tumor. However, post-surgery/-biopsy histopathology evaluation is almost invariably required to address the differential diagnosis of a testicular mass [33].

Histology features of testicular metastases are quite different from primary tumors of the testis. The former present as a nodule of small nests of tumor cells more commonly located in the epididymis and paraepididymal area, with a widespread involvement in the interstitium and the relative sparing of the seminiferous tubules [17]. Interstitial cell tumors or early invasive seminoma may present similar features [17]. However, the absence of seminiferous tubular involvement is a distinguishing aspect of metastatic lesions [17,23]. Extensive vascular and lymphatic invasion of parenchyma and tunica albuginea, multifocality or bilaterality are also features suggestive of metastases from solid malignancies. The immunostaining positivity for epithelial membrane antigen (EMA) and placental alkaline 
phosphatase negativity are consistent with a secondary tumor [26]. Similarly, the absence of EMA-positive immature testicular germ cells are also features favoring metastasis rather than primary testicular tumors [26].

Even though, the rarity of metastatic involvement of testis remains unexplained, it may be due to blood-testis and blood-epididymis barrier [34,35]. The tight junctions between Sertoli cells and between epididymis epithelial cells respectively, build a functional barrier of utmost competence [36]. These barriers create a unique anatomical, physiological and immunological microenvironment that restrict the passage of molecules and cells from entering or exiting the lumen $[35,36]$. This condition allows the proper development of the germ cells into fully functional sperm, most likely limiting metastatic deposits as well $[35,36]$. It has also been suggested that low temperature in the scrotum creates an unfavorable environment for the seeding of metastases [17,34-37]. However, molecular mechanisms allowing the blood-testis and bloodepididymis barriers to prevent metastatic spread to testis and how metastases overcome these protective mechanisms remain still unclear.

Inguinal lymph nodes are not a known site of metastatic spread from MTC. Metastases to inguinal lymph nodes are more commonly involved by cells from lymphoma and other malignant tumors located in the skin of lower extremities, in the scrotum, penis, vulva, clitoris, lower third of the vagina, anal canal, and infraumbilical region of the anterior abdominal wall. Melanoma or squamous cell carcinoma arising on the skin of the trunk may also metastasize to the inguinal lymph nodes. Rarely prostate, testicular or colon primary malignancies metastasize to inguinal lymph nodes $[38,39]$. When this happens, previous inguinal, pelvic or scrotal surgery may have altered lymphatic drainage [40]. Injured lymphatics may harbor new anastomoses between testicular and inguinal/pelvic lymphatic plexes, providing a potential direct way of metastatic spread to the inguinal lymph nodes [41]. Alternatively, the involvement of the adjacent anterior abdominal wall by micrometastasis or preexisting aberrant lymphatic drainage route have been postulated [41].

It is presumable that MTC metastases reached the testis first and then the inguinal lymph node via the infiltration of the rete testis. However, it is impossible to establish whether metastatic spread occurred vice versa or simultaneously.

Another interesting aspect of the present case, lies in the unexpectedly low levels of serum calcitonin and CEA in relation to the widespread dissemination of the disease. Calcitonin is a specific serum marker of MTC [1]. Preoperative calcitonin levels are very useful for both diagnosis and staging [1,2]. In case of nodal metastases, basal calcitonin levels commonly range between $10-40 \mathrm{ng} / \mathrm{ml}$ (normal range, $<10 \mathrm{ng} / \mathrm{ml}$ ), whereas distant metastases are usually associated with a calcitonin level $>150 \mathrm{ng} / \mathrm{ml}$ and often $>1000 \mathrm{ng} / \mathrm{ml}[6,16]$. Moreover, CEA may be increased in more than $50 \%$ of MTC patients and may be useful especially when preoperative calcitonin is within normal range [16]. A preoperative CEA serum level $>30 \mathrm{ng} / \mathrm{ml}$ predicts poor prognosis and indicates that surgery may not be curative. CEA levels $>100 \mathrm{ng} / \mathrm{ml}$ suggest extensive lymph node involvement and distant metastases. Increasing CEA levels with stable calcitonin suggest tumor dedifferentiation and worse prognosis $[6,16]$. Serum calcitonin and CEA measurements 2-6 months after the surgery are recommended to detect residual disease. Patients with undetectable serum calcitonin (basal and after stimulation test) and normal CEA values are virtually cured, being approximately $3-5 \%$ their 5 -year recurrence rate $[6,13]$. High basal serum calcitonin values $\geq 6$ months after surgery are suggestive of residual disease. Moreover, calcitonin and CEA doubling times strongly predict disease progression and reduced survival $[42,43]$. In our opinion, the low serum levels of calcitonin and CEA (175 pg/ml and $22 \mathrm{ng} / \mathrm{ml}$, respectively), despite lung, bone, testicular and inguinal lymph node metastases, are consistent with the low aggressiveness and the smoldering progression of the disease. These biological features may be not rarely seen in patients with MTC.

\section{Conclusions}

To the best of our knowledge, this is the first case report on testicular metastasis of MTC. Also inguinal lymph node involvement as a site of relapsing MTC has never been described before. In this patient, MTC metastases to the testis and inguinal lymph node were associated with disseminated disease, which is commonly observed in testicular metastases from solid malignancies. The present report, beyond its rarity, emphasizes that physicians need to consider testis and inguinal lymph nodes as an unusual, but possible site of metastases from MTC, even in the presence of relatively low serum markers of malignancy.

\section{Consent}

Written informed consent was obtained from the patient for publication of this Case report and any accompanying images. A copy of the written consent is available for review.

\section{Abbreviations}

$\beta$-HCG: $\beta$-human chorionic gonadotropin; CEA: Carcinoembrionic antigen; CT: Computed tomography; FDG-PET: 18-Fluorodeoxyglucose Positron Emission Tomography; EMA: Epithelial membrane antigen; FMTC: Familial medullary thyroid cancer; MTC: Medullary thyroid cancer; MEN: Multiple endocrine neoplasia; RET: Rearranged during transfection proto-oncogene; TTF-1: Thyroid transcription factor-1. 


\section{Competing interests}

The authors declare that they have no competing interests.

\section{Authors' contributions}

Acquisition of medical report of the patient: MA, AB, RB, VP, FT. Analysis and interpretation of data: $M A, A B, S M C, F T$. Review of the literature: $A B, F T$. Drafting of the manuscript: FT, AB, SMC, MA. Histopathology analysis: SS. All authors read and approved the final manuscript.

\section{Author details}

${ }^{1}$ Regina Elena National Cancer Institute, Endocrinology Unit, Via Elio Chianesi 53, I- 00144 Rome, Italy. ${ }^{2}$ Department of Urology, Regina Elena National Cancer Institute, Via Elio Chianesi 53, Rome, Italy. ${ }^{3}$ Department of Pathology, Regina Elena National Cancer Institute, Via Elio Chianesi 53, Rome, Italy. ${ }^{4}$ Endocrinology Unit, Università Cattolica, Largo F. Vito, 800168 Rome, Italy. ${ }^{5}$ Department of Systems Medicine, Chair of Medical Oncology, Tor Vergata University of Rome, Via Montpellier, 100133 Rome, Italy.

Received: 21 June 2014 Accepted: 29 September 2014 Published: 11 October 2014

\section{References}

1. Kloos RT, Eng C, Evans DB, Francis GL, Gagel RF, Gharib H, Moley JF, Pacini $F$, Ringel MD, Schlumberger M, Wells SA Jr: Medullary thyroid cancer: management guidelines of the American Thyroid Association. Thyroid 2009, 19:565-612.

2. NCCN Clinical Practice Guidelines in Oncology: Thyroid Carcinoma, Version 2.2013. http://www.nccn.org, Accessed on June 2014

3. Wohllk N, Cote GJ, Bugalho MM, Ordonez N, Evans DB, Goepfert H, Khorana S, Schultz P, Richards CS, Gagel RF: Relevance of RET protooncogene mutations in sporadic medullary thyroid carcinoma. J Clin Endocrinol Metab 1996, 81:3740-3745.

4. Elisei R, Romei C, Cosci B, Agate L, Bottici V, Molinaro E, Sculli M, Miccoli P, Basolo F, Grasso L, Pacini F, Pinchera A: RET genetic screening in patients with medullary thyroid cancer and their relatives: experience with 807 individuals at one center. J Clin Endocrinol Metab 2007, 92:4725-4729.

5. Saad MF, Ordonez NG, Rashid RK, Guido JJ, Hill CS Jr, Hickey RC, Samaan NA: Medullary carcinoma of the thyroid. A study of the clinical features and prognostic factors in 161 patients. Medicine (Baltimore) 1984, 63:319-342.

6. Pacini F, Castagna MG, Cipri C, Schlumberger M: Medullary thyroid carcinoma. Clin Oncol 2010, 22:475-485.

7. Börcek P, Asa SL, Gentili F, Ezzat S, Kiehl TR: Brain metastasis from medullary thyroid carcinoma. BMJ Case Rep 2010, 29. doi:10.1136/ bcr.09.2010.3301.

8. Bhatoe HS, Badwal S, Dutta V, Kannan N: Pituitary metastasis from medullary carcinoma of thyroid: case report and review of literature. J Neurooncol 2008, 89:63-67.

9. Ricciato MP, Lombardi CP, Raffaelli M, De Rosa A, Corsello SM: Metastatic breast involvement from medullary thyroid carcinoma: a clue to consider the need of early diagnosis and adequate surgical strategy. Thyroid 2010, 20:831-832.

10. Kebebew E, Ituarte PH, Siperstein AE, Duh QY, Clark OH: Medullary thyroid carcinoma: clinical characteristics, treatment, prognostic factors, and a comparison of staging systems. Cancer 2000, 88:1139-1148.

11. Esfandiari NH, Hughes DT, Yin H, Banerjee M, Haymart MR: The Effect of Extent of Surgery and Number of Lymph Node Metastases on Overall Survival in Patients with Medullary Thyroid Cancer. J Clin Endocrinol Metab 2014, 99:448-454.

12. Dottorini ME, Assi A, Sironi M, Sangalli G, Spreafico G, Colombo L: Multivariate analysis of patients with medullary thyroid carcinoma. Prognostic significance and impact on treatment of clinical and pathologic variables. Cancer 1996, 77:1556-1565.

13. Modigliani E, Cohen R, Campos JM, Conte-Devolx B, Maes B, Boneu A, Schlumberger M, Bigorgne JC, Dumontier P, Leclerc L, Corcuff B, Guilhem I: Prognostic factors for survival and for biochemical cure in medullary thyroid carcinoma: results in 899 patients. The GETC Study Group. Groupe d'étude des tumeurs à calcitonine. Clin Endocrinol (Oxford) 1998, 48:265-273.
14. Wells SA Jr, Gosnell JE, Gagel RF, Moley J, Pfister D, Sosa JA, Skinner M Krebs A, Vasselli J, Schlumberger M: Vandetanib for the treatment of patients with locally advanced or metastatic hereditary medullary thyroid cancer. J Clin Oncol 2010, 28:767-772.

15. Torino F, Paragliola RM, Barnabei A, Corsello SM: Medullary thyroid cancer: a promising model for targeted therapy. Curr Mol Med 2010, 10:608-625.

16. Roy $M$, Chen $H$, Sippel RS: Current understanding and management of medullary thyroid cancer. Oncologist 2013, 18:1093-1100.

17. Haupt HM, Mann RB, Trump DL, Abeloff MD: Metastatic carcinoma involving the testis. Clinical and pathologic distinction from primary testicular neoplasms. Cancer 1984, 54:709-714.

18. Tiltman AJ: Metastatic tumours in the testis. Histopathology 1979, 3:31-37.

19. Dutt N, Bates AW, Baithun SI: Secondary neoplasms of the male genital tract with different patterns of involvement in adults and children. Histopathology 2000, 37:323-331.

20. Pienkos EJ, Jablokow VR: Secondary testicular tumors. Cancer 1972, 30:481-485.

21. García-González R, Pinto J, Val-Bernal JF: Testicular metastases from solid tumors: an autopsy study. Ann Diagn Pathol 2000, 4:59-64.

22. Grignon DJ, Shum DT, Hayman WP: Metastatic tumours of the testes. Can J Surg 1986, 29:359-361.

23. Patel SR, Richardson RL, Kvols L: Metastatic cancer to the testes: a report of 20 cases and review of the literature. J Urol 1989, 142:1003-1005.

24. Bhasin SD, Shrikhande SS: Secondary carcinoma of testis-a clinicopathologic study of 10 cases. Indian J Cancer 1990, 27:83-90.

25. Sharma MC, Sudha K, Singh MK, Chahal R, Sood R: Metastatic carcinoma involving the testes. Indian J Pathol Microbiol 1996 39:293-296.

26. Lu LY, Kuo JY, Lin ATL, Chang YH, Chen KK, Pan CC, Chang LS: Metastatic Tumors Involving the Testes. J Urol ROC 2000, 11:12-17.

27. Ulbright TM, Young RH: Metastatic carcinoma to the testis: a clinicopathologic analysis of 26 nonincidental cases with emphasis on deceptive features. Am J Surg Pathol 2008, 32:1683-1693.

28. Nistal M, Gonzalez-Peramato P, Paniagua R: Secondary testicular tumors. Eur Urol 1989, 16:185-188.

29. Hanash KA, Carney JA, Kelalis PP: Metastatic tumors to testicles: routes of metastasis. J Urol 1969, 102:465-468.

30. Wang WS, Chiou TJ, Lu SH, Liu SM, Chen PM: Non-small cell lung cancer with testicular metastasis: a case report. Chin Med J (Taipei) 1996, 58:54-57.

31. Moore JB, Law DK, Moore EE, Dean CM: Testicular mass: an initial sign of colon carcinoma. Cancer 1982, 49:411-412.

32. Wishami MM: Detailed anatomy of the internal spermatic vein and ovarian vein: Human cadaver study and operative spermatic venography: clinical aspects. J Urol 1991, 145:780-784.

33. Price EB, Mostofi FK: Secondary carcinoma of the testis. Cancer 1957 10:592-595

34. Salesi N, Fabi A, Di Cocco B, Marandino F, Pizzi G, Vecchione A, Cognetti F: Testis metastasis as an initial manifestation of an occult gastrointestinal cancer. Anticancer Res 2004, 24:1093-1096.

35. Bart J, Groen HJ, van der Graaf WT, Hollema H, Hendrikse NH, Vaalburg W, Sleijfer DT, de Vries EG: An oncological view on the blood-testis barrier. Lancet Oncol 2002, 3:357-363.

36. Mital P, Hinton BT, Dufour JM: The blood-testis and blood-epididymis barriers are more than just their tight junctions. Biol Reprod 2011, 84:851-858.

37. Huang E, Teh BS, Mody DR, Carpenter LS, Butler EB: Prostate adenocarcinoma presenting with inguinal lymphadenopathy. Urology 2003, 61:463.

38. Komeya M, Sahoda T, Sugiura S, Sawada T, Kitami K: A case of metastatic prostate adenocarcinoma to an inguinal lymph node. Central Eur J Urol 2012, 65:96-97.

39. Ismail M, Zaman F, Baithun S, Nargund V, Pati J, Masood J: Inguinal lymph node metastases from a testicular seminoma: a case report and a review of the literature. J Med Case Rep 2010, 4:378.

40. Corby HM, Lynch TH, Fitzpatrick JM, Smith JM: Inguinal lymph node metastases from a testicular tumor. Br J Urol 1996, 77:923-924.

41. McGraw S, Thakkar J, Mehta D: Inguinal lymph node metastasis of colon cancer. Indian J Med Paediatr Oncol 2011, 32:168-170. 
42. Barbet J, Campion L, Kraeber-Bodéré F, Chatal JF, The GTE Study Group: Prognostic impact of serum calcitonin and carcinoembryonic antigen doubling-times in patients with medullary thyroid carcinoma. J Clin Endocrinol Metab 2005, 90:6077-6084.

43. Laure Giraudet A, Al Ghulzan A, Aupérin A, Leboulleux S, Chehboun A, Troalen F, Dromain C, Lumbroso J, Baudin E, Schlumberger M: Progression of medullary thyroid carcinoma: assessment with calcitonin and carcinoembryonic antigen doubling times. Eur J Endocrinol 2008, 158:239-246.

doi:10.1186/1472-6823-14-84

Cite this article as: Appetecchia et al.: Testicular and inguinal lymph node metastases of medullary thyroid cancer: a case report and review of the literature. BMC Endocrine Disorders 2014 14:84.

\section{Submit your next manuscript to BioMed Central and take full advantage of:}

- Convenient online submission

- Thorough peer review

- No space constraints or color figure charges

- Immediate publication on acceptance

- Inclusion in PubMed, CAS, Scopus and Google Scholar

- Research which is freely available for redistribution 